\title{
Anomalous Origin of the Left Coronary Artery from the Pulmonary Artery. Report of an Adult Case
}

\author{
Celso K. Takimura, Allyson Nakamoto, Viviane T. Hotta, Monica F. Campos, Mário Málamo, \\ Roberto Otsubo
}

São Paulo, SP - Brazil

\begin{abstract}
We report the clinical findings, pathophysiology, diagnostic characteristics, and surgical repair of anomalous origin of the left coronary artery from the pulmonary artery in a 26-year-old female patient with a clinical diagnosis of coronary heart disease.
\end{abstract}

Anomalous origin of the left coronary artery from the pulmonary artery is a rare congenital defect, and its incidence is estimated in 1:300,000 live births ${ }^{1}$. The clinical evolution varies according to the degree of collateral coronary circulation developed after birth. Anomalous origin of the left coronary artery from the pulmonary artery results in elevated mortality during the first year of life, and only $10 \%$ to $15 \%$ of the individuals with this defect reach adulthood ${ }^{2}$. The objective of this study was to report the case of an adult with this rare anomaly.

\section{Case Report}

A 26-year-old black female police officer reported that, 2 months prior to the diagnosis, she had been experiencing intense, sharp, precordial pain not related to physical exertion accompanied by fatigue on strenuous exertion and palpitations. As personal antecedents, she reported several hospitalizations during childhood due to "heart enlargement," and fatigue on great exertion during adolescence. She reported no risk factors for coronary atherosclerotic disease and no familial antecedents of heart disease.

On physical examination, the patient was found to be in regular general condition, acyanotic, and had no characteristic facies. She weighed $57 \mathrm{~kg}$ and was $1.80 \mathrm{~m}$ tall. Her blood pressure was $112 / 70 \mathrm{mmHg}$, and her heart rate was

Hospital Santa Cruz - São Paulo

Mailing address: Celso Kiyochi Takimura - Serviço de Cardiologia Invasiva S. Arie Ltda - Hemodinâmica - Hospital Santa Cruz - Rua Santa Cruz, 398 - 04122-000 São Paulo, SP, Brazil - Email: takimura@uol.com.br

English version by Stela Maris C. e Gandour 80bpm. Her peripheral pulses were present, symmetric, and of normal amplitude. Her cardiac auscultation revealed rhythmic and normal cardiac sounds of regular intensity and an early-systolic murmur (+/4+) in the mesocardium. The respiratory tract revealed no abnormalities on examination.

The chest X-ray revealed a slight enlargement in the cardiac area due to the left ventricle and normal pulmonary vessels.

The electrocardiogram showed sinus rhythm, a heart rate of $85 \mathrm{bpm}, \mathrm{QRS}$ axis at $-60^{\circ}$, Q waves in D1 and aVL with inverted $\mathrm{T}$ waves in these leads, indicating an inactive area in the high lateral wall, and a pattern suggestive of left ventricular hypertrophy.

The exercise test was effective with no precordialgia, but revealed a 4-mm straightened depression of the ST segment at exertional peak, indicating myocardial ischemia.

The two-dimensional echocardiogram showed a slight left ventricular dilation, moderate symmetric myocardial hypertrophy, preserved systolic performance, and prolapse of the mitral valve with slight valvular incompetence. No alterations in the great vessels, coronary arteries, or septal defects were observed.

The patient then underwent cardiac catheterization for diagnostic clarification. The procedure was performed via the femoral route according to the technique of Seldinger. The manometry of the right and left chambers was normal. The right coronary artery was of a high caliber, tortuous, and, through collateral vessels, it retrogradely filled the left coronary artery, which was well developed and connected to the pulmonary trunk (fig. 1). Contrast injection in the left Valsalva's sinus showed no artery originating from this site (fig. 2). Left ventriculography was not performed because of a mild allergic reaction triggered by the iodine contrast medium.

With the diagnosis of anomalous origin of the left coronary artery from the pulmonary artery, the patient was referred for surgery. However, she refused to undergo surgery, and is currently in stable condition, using no cardiovascular medications. She is not limited in her daily activities. 


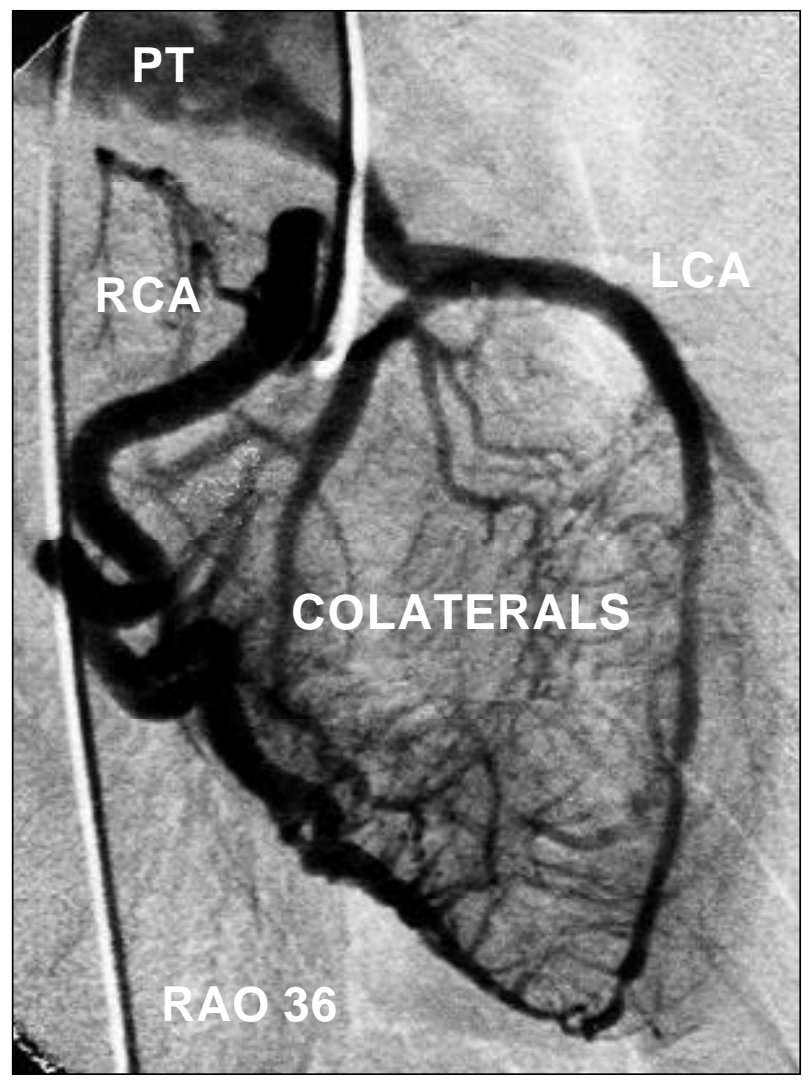

Fig. 1 - Coronary angiography in the right anterior oblique view (RAO), 36 degrees, revealing a right coronary artery (RCA) of righ tortuous caliber and filling of the left coronary artery (LCA) via collateral vessels. The left coronary artery was well developed and was connected to the pulmonary trunk (PT).

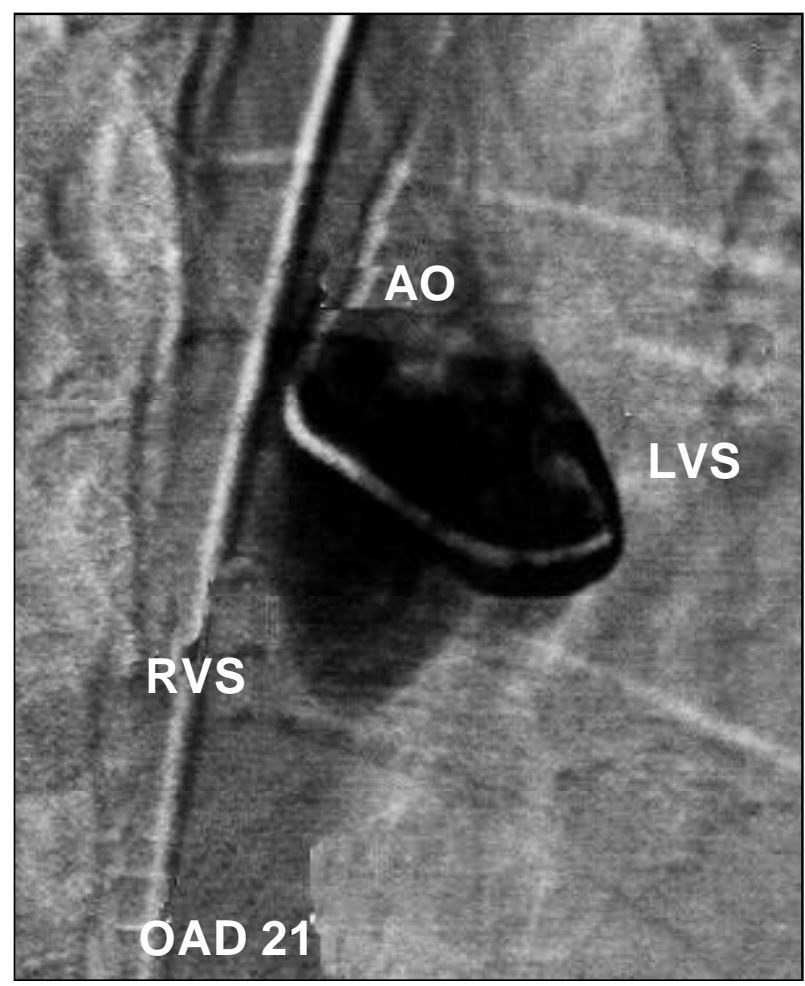

Fig. 2 - Right anterior oblique view (RAO), 21 degrees. Contrast injection in the left Valsalva's sinus (LVS) of the aorta (Ao) evidenced no artery origin in this site. RVS - right Valsalva's sinus.
Origin of the left coronary artery from the pulmonary artery

\section{Discussion}

Anomalous origin of the left coronary artery from the pulmonary artery or Bland- Garland-White syndrome is a rare anomaly, whose incidence is estimated as 1:300,000 live births, accounting for $0.24 \%$ of congenital heart diseases ${ }^{1}$. Usually, it manifests as an isolated defect, but, in 5\% of cases, it may be associated with other heart anomalies, such as ventricular septal defect, atrial septal defect, coarctation of the aorta, and other multiple anomalies ${ }^{3}$.

Anomalous origin of the left coronary artery from the pulmonary artery has 2 forms of presentation depending on the age bracket in which it manifests: an infantile and an adult form ${ }^{4}$. The infantile or immature form is characterized by paucity of the collateral coronary circulation, which may result in myocardial infarction, heart failure, or sudden death. Mortality in the first year of life, even with clinical treatment, is estimated to be as high as $80 \%$ to $90 \%$. The clinical expression of the syndrome results from evolving morphological-functional alterations in pulmonary circulation that occur after birth. In the first 2 months, as blood pressure is maintained elevated in the pulmonary region (fetal pattern), circulation in the left coronary artery is performed in an antegrade way, and, therefore, symptom onset or occurrence of sudden death is extremely uncommon in this age bracket. From then on, as pulmonary pressure decreases, blood flow in the left coronary artery follows a retrograde pattern through the collateral branches of the right coronary artery. The clinical manifestations result from myocardial ischemia and can be as follows: fatigue and crying when being fed, irritability, sweating, and paleness.

The adult or mature form of anomalous origin of the left coronary artery from the pulmonary artery may occur in children, and it occurs necessarily in adults in approximately $10 \%$ to $15 \%$ of cases. It is characterized by exuberance in the collateral coronary circulation, which allows survival until adulthood, with cases being reported at the age of 72 years ${ }^{5}$. The patients may be asymptomatic or experience fatigue, dyspnea on exertion, angina pectoris, cardiac arrhythmia, or sudden death. Approximately 150 cases have already been reported in the literature, 5 of which were in Brazil ${ }^{6-9}$.

Wesselhoeft et $\mathrm{al}^{2}$ classified the clinical spectrum and the presentation mode of anomalous origin of the left coronary artery from the pulmonary artery as follows: (1) infantile syndrome: the most common. Patients develop acute episodes of respiratory insufficiency, cyanosis, irritability, and profuse sweating. Most of these children die suddenly before the age of 2 years; (2) mitral regurgitation: characterized by mitral regurgitation murmur, congestive heart failure, cardiomegaly, and atrial arrhythmias in children, adolescents, or adults; (3) syndrome of the continuous murmur: occurs in asymptomatic adults or adults with angina pectoris. A continuous murmur is auscultated and results from the great volume of blood flowing through the collateral branches between the right and left coronary arteries; (4) sudden death in adolescents or adults: most patients are asymptomatic, but some may experience angina pectoris on exertion, cardiac arrhythmias, and sudden death. 
During childhood, our patient had heart failure, which resulted in several hospital admissions (the infantile syndrome according to the classification by Wesselhoeft et $\mathrm{al}^{2}$ ). After this phase, she evolved in an oligosymptomatic way, with adequate growth and development, living a normal life, including a normal professional life. The current findings of precordial pain and fatigue on strenuous exertion probably result from myocardial ischemia due to failure in the collateral circulation associated with compensatory myocardial hypertrophy.

On electrocardiography, anomalous origin of the left coronary artery from the pulmonary artery has characteristic ${ }^{3}$ alterations compatible with infarction of the anterolateral wall, frequent deviation of the electric axis to the left, and left ventricular hypertrophy, as seen in the present case.

Two-dimensional Doppler echocardiography is considered the major support method for diagnosing anomalous origin of the left coronary artery from the pulmonary artery ${ }^{4}$. This examination, however, has limitations. When an increase in pulmonary pressure exists, in the case of neonates and children with left ventricular failure, an antegrade flow in the left coronary artery may occur. In addition, in young children, the right coronary artery may not be dilated enough to lead to the suspicion of anomalous origin of the left coronary artery from the pulmonary artery. The echocardiography performed in the present case did not show the anomaly, revealing only mild dilation of the left ventricle, moderate and symmetric myocardial hypertrophy, and prolapse of the mitral valve with mild incompetence.

Other noninvasive examinations that are useful in diagnosing and characterizing this syndrome are as follows: transesophageal echocardiography, pharmacologic stress echocardiography, thallium scintigraphy, computerized tomography, and magnetic resonance imaging.

Cardiac catheterization is indicated for suspected cases of anomalous origin of the left coronary artery from the pulmonary artery, in which the echocardiogram does not reveal the abnormality. Three angiographic criteria were established for the diagnosis of anomalous origin of the left coronary artery from the pulmonary artery as follows: (1) retrograde filling of the left coronary artery; (2) connection of this vessel with the pulmonary trunk; (3) absence of left coronary artery originating from the aorta ${ }^{4}$. This method recommends selective injection in the right coronary artery, which is usually dilated, providing collateral branches to the left coronary artery. Then, the left coronary artery contrasts in a retrograde manner as far as its connection with the pulmonary trunk. Direct injection in the pulmonary trunk with the angiographic balloon catheter or selective injection in the left coronary artery connected to the pulmonary trunk may be performed.

Once the diagnosis of anomalous origin of the left coronary artery from the pulmonary artery is established, early surgical repair for correction of the defect and prevention of complications and sequelae inherent in the natural history of the disease is mandatory ${ }^{3}$. The surgical technique of election for correction of this anomaly is reimplantation with translocation of the left coronary artery from the pulmonary trunk to the aorta ${ }^{10}$, which is possible most of the time ${ }^{3}$. If this technique cannot be applied, "tunneling" or the Takeuchi technique ${ }^{11}$ is recommended; this technique consists of creating an intrapulmonary tunnel to connect the left coronary artery to the aorta. Other surgical options are the simple ligature of the left coronary artery and the performance of venous or arterial grafts. Clinical evolution and functional recovery of the left ventricle depend on the degree and extension of preoperative ventricular dysfunction. However, independent of the technique used, these patients may have cardiac arrhythmias and sudden death.

In summary, our case of Bland-Garland-White syndrome, in its adult or mature form, draws attention to the possibility, even though rare, of diagnosing anomalous origin of the left coronary artery from the pulmonary artery in young adults with mitral insufficiency, heart failure, cardiac arrhythmias, or myocardial ischemia.

\section{References}

1. Keith JD. The anomalous origin of the left coronary artery from the pulmonary artery. Br Heart J 1959; 21: 149-61.

2. Wesselhoft H, Fawcet JS, Johnson AL. Anomalous origin of the left coronary from the pulmonary trunk: its clinical spectrum, patology and pathophysiology, based on a review of 140 cases with seven further cases. Circulation 1968; 38: 403-25.

3. Amaral F, Carvalho JS, Granzotti JA, Shinebourne EA. Origem anômala da artéria coronária esquerda do tronco pulmonar: perfil clínico e resultados a médio prazo do tratamento cirúrgico. Arq Bras Cardiol 1999; 72: 307-13.

4. Culham JAG. Abnormalities of the Coronary Arteries. In: Freedom RM, Mawson JB, Yoo SJ, Benson LN, eds. Congenital Heart Disease. Textbook of Angiocardiography. Armonk, NY: Futura Publishing Company Inc., 1997: 862-6.

5. Fierens C, Budts W, Denef B, Van De WerfF. A 72 year old woman with ALCAPA. Heart 2000; 83: E2.

6. Oliveira AS, Diament J, Carvalho VB, Arie S, Macruz R, Zerbini EJ. Anomalous origin of the left coronary artery from the pulmonary artery: surgical repair of an unusual form. J Cardiovasc Surg 1977; 18: 599-605.

7. Oliveira SF, Ramires JAF, Meneguetti JC, et al. Anomalias congênitas de artérias coronárias: possível causa de insuficiência coronária. Arq Bras Cardiol 1988; 50: $285-91$

8. Mansur AP, Ramires JAF, Oliveira SF, Favarato D. Angina de esforço em paciente adulto com origem anômala de artéria coronária esquerda. Arq Bras Cardiol 1990; 55: 43-5.

9. Trajano A, Rodrigues LH, Miller VM, Gottschall CA. Anomalia da coronária esquerda e infarto do miocárdio. Arq Bras Cardiol 1992; 58: 379-82.

10. Almeida SL, Mazzieri R, Berlinck MF, Souza JM, Oliveira SA. Correção cirúrgica precoce da artéria coronária esquerda com origem em tronco pulmonar: evolução tardia. Arq Bras Cardiol 1990; 55: 319-23.

11. Takeuchi S, Imamura H, Katsumoto K, et al. New surgical method for repair of anomalous left coronary artery from pulmonary artery. J Thorac Cardiovasc Surg 1979; 78: 7-11 